\title{
ANALISIS PENDAPATAN DAN NILAI TAMBAH OTAK-OTAK IKAN BANDENG (Chanos chanos) DI KECAMATAN LAMONGAN (KOTA) KABUPATEN LAMONGAN
}

\author{
Nur Khoiriyah', Moch Saad ${ }^{1 *}$, Endah Sih Prihatini' ${ }^{1}$, Agung Pamuji Rahayu ${ }^{1}$ \\ ${ }^{1}$ Fakultas Perikanan, Universitas Islam Lamongan \\ *E-mail: amochsaad22@gmail.com
}

\begin{abstract}
ABSTRAKSI
Ikan bandeng merupakan komoditas andalan pengembangan budidaya tambak air payau dan tawar. Ikan Bandeng memiliki beberapa keunggulan dibandingkan dengan spesies lainnya, antara lain adalah teknik pembenihannya mudah dikuasai, tahan terhadap perubahan lingkungan yang ekstrim, tanggap terhadap pakan buatan yang telah tersedia secara komersial, dapat dipelihara dengan kepadatan tinggi dan tidak bersifat kanibalisme. Peluang usaha ikan Bandeng otak-otak ikan Bandeng ini sangat terbuka luas mulai dari penawaran kepada konsumen yang menyukai otak-otak Ikan Bandeng. Peluang usaha Ikan Bandeng sangat menjanjikan untuk sukses dalam kurun waktu yang tidak terlalu lama dan tentu saja akan mendapatkan profit yang tidak sedikit bagi kami untuk mengembangkan usaha otak-otak Ikan Bandeng. Adapun tujuan dari penelitian ini adalah untuk mengetahui seberapa besar keuntungan yang diterima dari pengolahan ikan bandeng menjadi otak-otak ikan bandeng, untuk menganalisis seberapa besar nilai tambah pengolaha ikan bandeng menjadi otak-otak ikan bandeng. Penelitian dilaksanakan pada bulan April-Mei 2019 pada usaha otak-otak Ikan Bandeng yang bertempat di Kecamatan Lamongan Kabupaten Lamongan. Metode penelitian yang digunakan adalah studi kasus dengan sengaja (purposive sample) adalah salah satu teknik sampling non random sampling dimana peneliti menentukan pengambilan sampel dengan cara menetapkan ciri-ciri khusus yang sesuai dengan tujuan penelitian sehingga diharapkan dapat menjawab permasalahan penelitian. Berdasarkan uraian hasil dan pembahasan, maka dapat disimpulkan pengolah Ikan Bandeng menjadi otak-otak Ikan Bandeng di Kecamatan Lamongan Kabupaten Lamongan memperoleh keuntungan sebesar Rp. 31.347.877 per delapan belas kali produksi selama satu bulan, pengolah Ikan Bandeng menjadi otak-otak Ikan Bandeng di Kecamatan Lamongan Kabupaten Lamongan menghasilkan nilai tambah sebesar Rp. 10.900/kg bahan baku.
\end{abstract}

Kata kunci : Otak-otak Ikan Bandeng, Analisis Pendapatan dan Nilai Tambah, Hayami

\section{PENDAHULUAN}

Sektor kelautan dan perikanan menjadi salah satu sumber bagi pertumbuhan ekonomi nasional. Hal ini terjadi dengan adanya daya dukung berupa kapasitas suplai yang besar dengan dukungan permintaan yang terus meningkat. Output sektor kelautan dan perikanan berupa ikan dan usaha pengolahan perikanan dapat di ekspor, pada sisi lain inputnya berasal dari sumberdaya domestik. Potensi industri hulu dan hilir yang besar, sehingga mampu 
menyerap tenaga kerja dalam jumlah besar. Selain hal tersebut, produk sektor kelautan dan perikanan memiliki sifat dapat diperbarui, sehingga mendukung bagi pembagunan berkelanjutan (Kementerian Kelautan dan Perikanan, 2016).

Ikan bandeng merupakan komoditas andalan pengembangan budidaya tambak air payau dan tawar. Ikan bandeng memiliki beberapa keunggulan dibandingkan dengan spesies lainnya, antara lain adalah teknik pembenihannya mudah dikuasai, tahan terhadap perubahan lingkungan yang ekstrim, tanggap terhadap pakan buatan yang telah tersedia secara komersial, dapat dipelihara dengan kepadatan tinggi dan tidak bersifat kanibalisme (Rachmansyah, 2004).

Mudahnya kerusakan ikan tersebut menjadi kendala bagi penjual di pasaran, oleh karena itu perlu adanya upaya untuk mengawetkan bahan makanan tersebut sehingga dapat diterima konsumen dalam keadaan yang masih layak dikonsumsi. Pengolahan ikan sangat penting dilakukan karena ikan merupakan komoditas yang tidak tahan lama atau mudah mengalami pembusukan, untuk itu keberadaan industri perikanan yang sangat penting karena olahan ikan dapat menjadi sumber pendapatan dimana olahan ikan menjadi suatu produk setengah jadi atau produk jadi yang lebih tahan lama dan siap dikonsumsi oleh konsumen serta bernilai ekonomis. Industrialisasi perikanan bagian yang tidak dapat dipisahkan dari sektor kelautan dan perikanan (Kementrian Kelautan dan Perikanan, 2016).

Adanya usaha pengolahan ikan bandeng sebagai salah satu usaha yang mengolah ikan bandeng menjadi berbagai produk baru yang memiliki nilai ekonomis yang tinggi setelah dilakukan proses pengolahan. Usaha ini mengolah ikan bandeng menjadi otak-otak bandeng. Sejauh ini belum diketahui kelayakannya. Berdasarkan latar belakang dilaksanakan penelitian yang berjudul analisis pendapatan dan nilai tambah otak-otak ikan bandeng (chanos-chanos) di Kecamatan Lamongan Kabupaten Lamongan.

\section{METODE PENLITIAN}

Kegiatan penelitian ini dilakukan di Kecamatan Lamongan (KOTA) Kabupaten Lamongan. Penelitian ini di lakukan pada bulan April 2019 hingga Mei 2019.

Dalam penelitian ini teknik sampling yang digunakan yaitu purposive sampling Menurut Sugiyono (2010) teknik untuk menentukan sampel penelitian dengan beberapa pertimbangan tertentu yang bertujuan agar data yang diperoleh nantinya bisa lebih representatif.

Data yang di kumpulkan merupakan data primer dan data skunder. Data primer merupakan data yang di peroleh secara langsung dari pelaku usaha dan pihak terkait baik melalui pengisian kuisioner maupun wawanacara. Sedangkan data sekunder merupakan data yang di peroleh melalui studi literatur dari artikel, jurnal, buku dan data pendukung lainnya.

Menghitung Nilai Tambah Tahu. Untuk mengetahui tujuan kedua dalam penelitian ini, digunakan metode analisis nilai tambah Hayami, dengan format tersaji pada Tabel 1. 
Tabel 1. Analisis nilai tambah

\begin{tabular}{|c|c|c|}
\hline No & Variabel & Hasil/nilai \\
\hline & Output, Input Dan Harga (Satuan) & \\
\hline 1. & Hasil Produksi Otak-Otak Bandeng (Kg/Bulan) & \\
\hline 2. & Bahan Baku (Kg/Bulan) & \\
\hline 3. & Tenaga Kerja (Hk/Bulan) & \\
\hline 4. & Faktor Konversi (1)/(2) & \\
\hline 5. & Koefisiensi Tenaga Kerja (3)/(2) & \\
\hline 6. & Harga Produk Rata-Rata $(\mathrm{Rp} / \mathrm{Kg})$ & \\
\hline \multirow[t]{2}{*}{7.} & Upah Rata-Rata (Rp/Hari) & \\
\hline & Keuntungan & \\
\hline 8. & Harga Bahan Baku (Rp/Kg) & \\
\hline 9. & Sumbangan Input Lain $(\mathrm{Rp} / \mathrm{Kg})$ & \\
\hline 10. & Nilai Produk $=(4) \mathrm{X}(6)(\mathrm{Rp} / \mathrm{Kg})$ & \\
\hline \multirow[t]{2}{*}{11.} & a). Nilai Tambah (10) - (8) - (9) $(\mathrm{Rp} / \mathrm{Kg})$ & \\
\hline & b). Rasio Nilai Tambah (11a) / (10) (\%) & \\
\hline \multirow[t]{2}{*}{12.} & a) Imbalan Tenaga Kerja (5) X (7) $(\mathrm{Rp} / \mathrm{Kg})$ & \\
\hline & b). Bagian Tenaga Kerja (12a) / (11a) (\%) & \\
\hline \multirow[t]{3}{*}{13.} & a). Keuntungan (11a)-(12a)/ (Rp/Kg) & \\
\hline & b). Tingkat Keuntungan (13a)/ (11a) (\%) & \\
\hline & Balas Jasa Untuk Faktor Produksi & \\
\hline \multirow[t]{4}{*}{14.} & Margin (10)-(8) (Rp/kg) & \\
\hline & a). Pendapat tenaga kerja (12a)/(14) \% & \\
\hline & b). Sumbangan input lain $(9) /(14) \%$ & \\
\hline & c). Keuntungan perusahaan (13a)/(14) \% & \\
\hline
\end{tabular}

\section{HASIL DAN PEMBAHASAN}

\section{Keadaan Umum Daerah Penelitian Kecamatan} Lamongan merupakan sebuah Kecamatan di Kabupaten Lamongan, Provinsi Jawa Timur indonesia. Kabupaten Lamongan adalah salah satu Kecamatan dari 27 Kecamatan yang berada di Kabupaten Lamongan, dengan jarak orbitas $0,5 \mathrm{~km}$ dari ibu kota, Lamongan $\pm 20 \mathrm{~km}$ arah kota Gresik (kota terdekat).

Kecamatan Lamongan yang mempunyai wilayah dengan beberapa bagian tersebut berpotensi dalam mata pencaharian di bidang pertanian dan perikanan, lokasi yang berada dekat dengan tambak menjadikan masyarakat di Kecamatan Lamongan memanfaatkan kondisi tersebut sebagai mata pencaharian mereka.
Cara pembuatan otak-otak ikan bandeng

Proses pengolahan otak-otak ikan bandeng dilakukan melalui beberapa tahap yaitu : persiapan bahan baku, pembersihan dan pengeluaran isi perut, pemisahan daging dengan kulit ikan, penggilingan daging ikan, pembuatan bumbu dan percampuran dengan daging, pengembalian adonan kedalam kulit, pegukusan, pendinginan, pengorengan dan pengemasan.

Pendapatan yang diperoleh dari Pengolahan Otak-otak Ikan Bandeng

Pengolahan ikan bandeng menjadi otak-otak ikan bandeng di Kecamatan Lamongan Kabupaten Lamongan memperoleh keuntungan sebesar Rp. 31.347.877 per delapan belas kali proses produksi selama satu bulan. 


\section{Analisis Data}

Berdasarkan data yang diperoleh dari kegiatan penelitian pada 2 usaha di Kecamatan Lamongan (KOTA) Kabupaten Lamongan maka dapat disajikan data sebagai berikut:

\section{Analisis Nilai Tambah yang diperoleh dari Pengolahan Otak- otak Ikan Bandeng}

Pengolahan ikan bandeng menjadi otak-otak ikan bandeng di Kecamatan Lamongan Kabupaten Lamongan menghasilkan nilai tambah sebesar Rp. 10.900/kg bahan baku.

\section{Biaya bahan baku}

Biaya bahan baku adalah nilai dari seluruh input usaha yang dikeluarkan dalam pengolahan ikan bandeng menjadi otak-otak ikan bandeng.

Dari hasil penelitian menunjukan bahwa biaya bahan baku yang dikeluarkan oleh pengolah ikan bandeng menjadi otak-otak adalah sebesar Rp. 18.000/Kg. Dalam satu bulan bahan baku yang digunakan adalah $234 \mathrm{~kg}$ dengan rata-rata 13 $\mathrm{Kg} /$ proses produksi. Besarnya biaya bahan baku yang dikeluarkan tergantung dari jumlah bahn baku yang digunakan. Sehingga biaya yang dikeluarkan oleh pengolah untuk biaya bahan baku selama satu bulan adalah sebesar Rp. 4.212.000 dengan rata-rata Rp. 234.000 /proses.

\section{Jumlah dan upah tenaga kerja.}

Dalam penelitian ini usaha pengolahan ikan bandeng menjadi otak-otak pada usaha otak-otak ikan bandeng mempunyai tenaga kerja sebanyak 3 orang. Dari jumlah tersebut, seluruh tenaga kerja merupakan tenaga kerja wanita. Para pekerja ini hampir setiap hari melakukan proses produksi. Dalam satu bulan penelitian terdapat 18 hari kerja aktif. Hasil penelitian menunjukan bahwa kisaran jam kerja dalam satu bulan produksi adalah 108 jam dengan jumlah hari kerja (hk) sebanyak 40,5 hk/bulan.

Hasil penelitian menunjukan bahwa upah tenaga kerja dihitung per $\mathrm{kg}$ produk otak-otak yaitu sebesar Rp. $2.692 / \mathrm{kg}$ untuk satu pekerja. Jadi, dalam satu bulan upah kerja yaitu sebesar Rp. 630.000 /pekerja dengan rata-rata Rp. 35.000 /proses produksi, sehingga biaya tenaga kerja yang dikeluarkan oleh pemilik usaha pengolahan ikan bandeng menjadi otak-otak untuk 3 pekerja adalah Rp. 1.980.000 /bulan dengan rata-rata Rp. 105.000/proses produksi, sedangkan upah rata-rata per hari kerja yaitu Rp. 46,666/hk.

\section{Biaya overhead pabrik}

Biaya overheard pabrik adalaha biaya produksi yang tidak langsung terhadap produk dan tidak masuk dalam biaya bahan baku maupun biaya tenaga kerja. Contoh biaya overhead pabrik adalah biaya yang timbul dari pemakaian bahan penolong atau penunjang, biaya peralatan serta penyusutan.

Adapun biaya overhead pabrik dalam penelitian ini tersaji pada Tabel 2. 
Tabel 2. Biaya overhead pabrik

\begin{tabular}{|c|c|c|c|c|c|c|}
\hline No & Bahan penunjang & Jumlah & Satuan & $\begin{array}{c}\text { Total } \\
\text { penggunaan } \\
\text { per bahan } \\
\text { baku (hari) }\end{array}$ & $\begin{array}{c}\text { Harga } \\
(\mathrm{Rp} / \mathrm{Kg})\end{array}$ & $\begin{array}{c}\text { Jumlah } \\
\text { (Rp) }\end{array}$ \\
\hline 1 & Bumbu giling & 1 & Paket & 18 & Rp. 100.000 & Rp.1.800.000 \\
\hline 2 & Kelapa parut & 1 & Paket & 18 & Rp. 70.000 & Rp.1.260.000 \\
\hline 3 & Garam & 2 & Bungkus & 18 & Rp. 1.000 & Rp.36.000 \\
\hline 4 & Gula & 1 & $\mathrm{Kg}$ & 18 & Rp. 15.000 & Rp.270.000 \\
\hline 5 & Telur & 2 & $\mathrm{Kg}$ & 18 & Rp. 18.000 & Rp.648.000 \\
\hline 6 & Penguat rasa & 2 & Lusin & 18 & Rp. 4.500 & Rp.162.000 \\
\hline 7 & Minyak goreng & 9 & Liter & 18 & Rp. 12.000 & Rp.1.944.000 \\
\hline 8 & Gas elpiji & 8 & $\mathrm{Kg}$ & 18 & Rp. 8.000 & Rp.1.152.000 \\
\hline \multicolumn{6}{|c|}{ Jumlah biaya bahan penunjang } & Rp.7.272.000 \\
\hline
\end{tabular}

Berdasarkan hasil penelitian biaya yang dikeluarkan oleh pengolah untuk biaya bahan penunjang dalam satu kali proses produksi $13 \mathrm{~kg}$ bahan baku yaitu bumbu giling yang digunakan sebanyak 1 paket adalah sebesar Rp. 100.000/paket, kelapa parut yang digunakan sebanyak 1 paket adalah sebesar Rp. 70.000/paket, garam dapur sebanyak 2 bungkus dengan harga Rp. 1000/bungkus, gula sebanyak $1 \mathrm{~kg}$ dengan harga $\mathrm{Rp}$. $15.000 / \mathrm{kg}$, telur sebanyak $2 \mathrm{~kg}$ dengan harga Rp. 18.000/kg, penguat rasa sebanyak 2 lusin dengan harga Rp. 4.500/lusin, minyak goreng yang digunakan sebanyak 9 liter dengan harga Rp. 12.000/liter, dan gas elpiji yang digunakan sebanyak $8 \mathrm{~kg}$ dengan harga Rp. 8000/kg.

Dalam satu bulan proses produksi, total penggunaaan bahan penunjang per bahan baku adalah sebanyak 18 kali, yaitu $234 \mathrm{~kg}$ ikan bandeng, sehingga total biaya bahan penunjang yang dikeluarkan untuk bumbu giling sebesar Rp. 1.800.000, kelapa parut sebesar Rp. 1.260.000, garam dapur sebesar Rp. 36.000, gula sebesar Rp. 270.000, telur sebesar Rp. 648.000, penguat rasa sebesar Rp. 162.000, minyak goreng sebesar Rp. 1.944.000, dan gas elpiji sebesar Rp. 1.152.000 total keseluruhan biaya bahan penunjang yang dikeluarkan oleh usaha pengolhan ikan bandeng menjadi otak-otak adalah sebesar Rp. 7.272.000.

\section{Biaya peralatan dan penyusutan}

Perencanaan pengadaan peralatan dari bahan baku yang efektif dan efisien dapat menjadikan kegiatan produksi berjalan lancar serta dapat meningkatkan hasil dan keuntungan bagi usaha pengolahan ikan bandeng menjadi otak-otak ikan bandeng. Rincian biaya penggunaan peralatan pada usaha pengolahan ikan bandeng menjadi otak-otak ikan bandeng di Kecamatan Lamongan. 
Tabel 3. Rincian biaya penggunaan peralatan pada usaha pengolahan ikan bandeng menjadi otak-otak ikan bandeng di Kecamatan Lamongan

\begin{tabular}{|c|c|c|l|l|l|l|}
\hline No & Jenis Alat & $\begin{array}{c}\text { Jumlah } \\
\text { (unit) }\end{array}$ & \multicolumn{1}{|c|}{$\begin{array}{c}\text { Harga } \\
(\mathrm{Rp})\end{array}$} & $\begin{array}{c}\text { Jumlah Biaya } \\
(\mathrm{Rp})\end{array}$ & $\begin{array}{c}\text { Umur } \\
\text { ekonomis } \\
\text { (bulan) }\end{array}$ & $\begin{array}{c}\text { Penyusutan } \\
\text { (Rp/Bulan })\end{array}$ \\
\hline 1 & Pisau & 8 & Rp.10.000 & Rp.80.000 & 24 & Rp.3,333 \\
\hline 2 & Baskom & 3 & Rp.25.000 & Rp.75.000 & 24 & Rp.3,125 \\
\hline 3 & Dandang & 2 & Rp.200.000 & Rp.400.000 & 24 & Rp.16,666 \\
\hline 3 & Wajan & 4 & Rp.45.000 & Rp.180.000 & 24 & Rp. 7.500 \\
\hline 5 & Kukusan & 2 & Rp.30.000 & Rp.60.000 & 24 & Rp.2.500 \\
\hline 6 & Penggiling & 1 & Rp.4.000.000 & Rp.4.000.000 & 60 & Rp.66.666 \\
\hline 7 & Kompor & 4 & Rp.150.000 & Rp.600.000 & 60 & Rp.10.000 \\
\hline 8 & Lengser & 10 & Rp.20.000 & Rp. 200.000 & 24 & Rp.8,333 \\
\hline & \multicolumn{1}{|l}{ Jumlah } & Rp.5.595.000 & & Rp.118.123 \\
\hline
\end{tabular}

total biaya peralatan yang dikeluarkan oleh usaha pengolahan ikan bandeng menjadi otak-otak pada usaha otak-otak bandeng di Kecamatan Lamongan Kabupaten Lamongan adalah Rp. 5.595.000. biaya peralatan yang terbesar untuk pembelian alat penggiling, dengan harga Rp. 4.000.000. dan biaya terendah yang dikeluarkan untuk pembelian lengser dengan harga Rp.20.000. secara keseluruhan nilai penyusutan peralatan sebesar Rp. 118.123 per bulannya.

Untuk jumlah harga pokok produksi dalam penelitian ini adalah jumlah biaya bahan baku ditambah jumlah upah tenaga kerja dan ditambah jumlah biaya overhead pabrik (biaya bahan penunjang dan biaya peralatan serta penyusutan).

Tabel 4. jumlah harga pokok produksi

\begin{tabular}{|c|c|c|}
\hline No & & Nilai (Rp) \\
\hline 1 & Biaya Bahan Baku & Rp. 4.212.000 \\
\hline 2 & Upah Tenaga Kerja & Rp. 1.980 .000 \\
\hline \multirow[t]{4}{*}{3} & $\begin{array}{l}\text { Biaya Overhead } \\
\text { Pabrik : }\end{array}$ & \\
\hline & $\begin{array}{l}\text { - Biaya Bahan } \\
\text { Penunjang }\end{array}$ & Rp. 7.272.000 \\
\hline & - $\quad$ Penyusutan & Rp.118.000 \\
\hline & Jumlah & Rp.13.582.123 \\
\hline
\end{tabular}

\section{Penerimaan dan Keuntungan}

Penerimaan merupakan hasil dari perkalian antara jumlah produksi otak-otak ikan bandeng yang dihasilkan dengan harga jual dengan satuan rupiah dalam proses produksi. Dari rumus penerimaan tersebut, dapat ditentukan jumlah penerimaan yang diperoleh dari penjualan produk otak-otak yaitu sebesar Rp. 45.630.000 hasil tersebut akan dikurangkan dengan biaya-biaya yang menyangkut proses pengolahan ikan bandeng menjadi otak-otak sehingga mendapatkan keuntungan bersih.

Dalam penelitian ini untuk menghitung keuntungan bersih, digunakan rumus perhitungan rugilaba selama satu bulan.

Harga pokok produksi merupakan komponen biaya terbesar dalam pengolahan ikan bandeng menjadi otak-otak yaitu sebesar Rp. 13.582.123 dari keseluruhan biaya yang dikeluarkan. Sedangkan beban operasi yang meliputi sewa bangunan, penerangan dan air bersih sebesar Rp. 700.000 dan untuk beban bunga serta pajak penghasilan tidak ada biaya yag dikenakan, karena dari hasil penelitian pengolah ikan bandeng menjadi otak-otak ikan 
bandeng menyatakan bahwa dalam usahanya tidak dikenakan biaya bunga atau pinjaman dan juga tidak ada potongan pajak dari usahanya.

Hasil perhitungan pada tabel memperlhatkan bahwa untuk mendapatkan keuntungan bersih, nilai pendapatan dari penjualan dikurangi dengan harga pokok produksi kemudian dikurangi dengan beban operasi serta dikurangi dengan beban bunga dan pajak penghasilan. Jadi, keuntungan bersih yang diperoleh dari pengolahan ikan bandeng menjadi otak-otak ikan bandeng adalah sebesar Rp.31.347.877/bulan.

\section{Nilai Tambah}

Nilai tambah merupakan nilai yang ditambahkan kedalam barang dan jasa yang dipakai oleh unit produksi dalam proses produksi sebagai biaya antara. Nilai yang ditambahkan ini sama dengan balas jasa atas ikut sertanya faktor produksi dalam proses produksi. Perhitungan nilai tambah pengolahan otak-otak bertujuan untuk mengetahui penambahan nilai dari proses pengolahan bahan baku menjadi otak-otak. Nilai tambah dihitung dari selisih antara nilai output (penerimaan) dan input (biaya total) yang dikeluarkan dalam proses pengolahan. Seluruh komponen analisis diukur dan dinyatakan dalam satuan satu kilogram $(1 \mathrm{Kg})$ bahan baku.

Tabel 5. Nilai Tambah

\begin{tabular}{|c|c|c|}
\hline No & Variabel & Hasil/nilai \\
\hline & $\begin{array}{l}\text { Output, Input Dan } \\
\text { Harga (Satuan) }\end{array}$ & \\
\hline 1. & $\begin{array}{l}\text { Hasil Produksi Otak- } \\
\text { Otak Bandeng } \\
\text { (Kg/Bulan) }\end{array}$ & $\begin{array}{c}234 \\
\mathrm{~kg} / \mathrm{bulan}\end{array}$ \\
\hline 2. & $\begin{array}{l}\text { Bahan Baku } \\
\text { (Kg/Bulan) }\end{array}$ & $\begin{array}{l}234 \\
\mathrm{~kg} / \text { bulan }\end{array}$ \\
\hline
\end{tabular}

\begin{tabular}{|c|c|c|}
\hline 3. & $\begin{array}{l}\text { Tenaga Kerja } \\
\text { (Hk/Bulan) }\end{array}$ & 40,5 \\
\hline 4. & $\begin{array}{l}\text { Faktor Konversi } \\
(1) /(2)\end{array}$ & 1 \\
\hline 5. & $\begin{array}{l}\text { Koefisiensi Tenaga } \\
\text { Kerja (3)/(2) }\end{array}$ & 0,173 \\
\hline 6. & $\begin{array}{l}\text { Harga Produk Rata- } \\
\text { Rata }(\mathrm{Rp} / \mathrm{Kg})\end{array}$ & 32.500 \\
\hline \multirow[t]{2}{*}{7.} & $\begin{array}{l}\text { Upah Rata-Rata } \\
\text { (Rp/Hari) }\end{array}$ & 46.666 \\
\hline & Keuntungan & \\
\hline 8. & $\begin{array}{l}\text { Harga Bahan Baku } \\
(\mathrm{Rp} / \mathrm{Kg})\end{array}$ & 18.000 \\
\hline 9. & $\begin{array}{l}\text { Sumbangan Input } \\
\text { Lain }(\mathrm{Rp} / \mathrm{Kg})\end{array}$ & 3600 \\
\hline 10. & $\begin{array}{l}\text { Nilai Produk = } \\
(4) \mathrm{X}(6)(\mathrm{Rp} / \mathrm{Kg})\end{array}$ & 32.500 \\
\hline \multirow[t]{2}{*}{11.} & $\begin{array}{l}\text { a). Nilai Tambah (10) } \\
-(8)-(9)(\mathrm{Rp} / \mathrm{Kg})\end{array}$ & 10.900 \\
\hline & $\begin{array}{l}\text { b). Rasio Nilai } \\
\text { Tambah (11a) / (10) } \\
\text { (\%) }\end{array}$ & $0,33 \%$ \\
\hline \multirow[t]{2}{*}{12.} & $\begin{array}{l}\text { a) Imbalan Tenaga } \\
\text { Kerja (5) X (7) } \\
(\mathrm{Rp} / \mathrm{Kg})\end{array}$ & 8,073 \\
\hline & $\begin{array}{l}\text { b). Bagian Tenaga } \\
\text { Kerja (12a) / (11a) } \\
(\%)\end{array}$ & $0,74 \%$ \\
\hline \multirow[t]{3}{*}{13.} & $\begin{array}{l}\text { a). Keuntungan (11a)- } \\
\text { (12a)/ }(\mathrm{Rp} / \mathrm{Kg})\end{array}$ & 2,827 \\
\hline & $\begin{array}{l}\text { b). Tingkat } \\
\text { Keuntungan (13a) / } \\
\text { (11a) }(\%)\end{array}$ & $0,26 \%$ \\
\hline & $\begin{array}{l}\text { Balas Jasa Untuk } \\
\text { Faktor Produksi }\end{array}$ & \\
\hline \multirow[t]{4}{*}{14.} & $\begin{array}{l}\text { Margin (10)-(8) } \\
(\mathrm{Rp} / \mathrm{kg})\end{array}$ & 14.500 \\
\hline & $\begin{array}{l}\text { a). Pendapat tenaga } \\
\text { kerja (12a)/(14) \% }\end{array}$ & $-14,491$ \\
\hline & $\begin{array}{l}\text { b). Sumbangan input } \\
\text { lain }(9) /(14) \%\end{array}$ & $-10,900$ \\
\hline & $\begin{array}{l}\text { c). Keuntungan } \\
\text { perusahaan }(13 a) /(14) \\
\%\end{array}$ & 0,019 \\
\hline
\end{tabular}

Dari hasil penelitian ini terdapat bahan baku ikan bandeng sebanyak $234 \mathrm{~kg} /$ bulan sehingga menghasilkan produk otak-otak sebanyak $234 \mathrm{~kg} /$ bulan dalam 18 kali produksi. Kisaran hari kerja berlangsung selama 5-7 hari kerja, sehingga hari kerja yang dicurahkan oleh 3 orang tenaga adalah 40,5 hari kerja sebulan. 
Fantor konversi merupakan perbandingan antara hasil yang diperoleh dengan banyak bahan baku yang digunakan dan bernilai 1,00. Artinya, untuk setiap satu $\mathrm{kg}$ ikan bandeng yang diolah akan diperoleh $1,00 \mathrm{~kg}$ otak-otak. Koefisien tenaga kerja diperoleh dari rasio antara jumlah hari kerja dengan bahan baku yang diolah. Hasil perhitungan diperoleh koefisien tenaga kerja sebesar 0,173 yang diartikan bahwa setiap tenaga kerja dalam 1 hari kerja mampu mengolah bahan baku sebanyak $0,173 \mathrm{~kg}$.

Harga rata-rata produk otakotak dalam pemasarannya Rp. $32.500 / \mathrm{kg}$. Harga rata-rata bahan baku sebesar Rp. 18.000/kg. Sumbangan input lain atau bahan penunjang bernilai Rp.3.600/kg. Bahan baku. Nilai produk merupakan perkalian antara faktor konversi dengan harga produk sebesar Rp. $32.500 / \mathrm{kg}$ bahan baku. Nilai produk ini dipengaruhi oleh besarnya nilai faktor konversi.

Nilai tambah pengolahan ikan bandeng menjadi otak-otak sebesar Rp. 10.900/kg bahan baku. Angka ini merupakan selisih antara nilai produk dengan harga bahan baku dan sumbangan input lain. Besarnya nilai tambah produk yang dipengaruhi oleh beberapa faktor diantaranya biaya sumbangan input lainnya selain biaya bahan baku. Rasio nilai tambah terhadap nilai produk sebesar 0,33 $\%$. Artinya, untuk setiap Rp. 100 nilai produk akan diperoleh nilai tambah Rp. 33. nilai tambah menunjukkan nilai yang besar. Hal ini disebabkan tingginya nilai produk, sementara harga bahan baku dan sumbangan input lain tidak begitu besar.

Imbalan tenaga kerja merupakan hasil perkalian anatara koefisien tenaga kerja dengan upah rata-rata yang nilainya $\mathrm{Rp} .8 .073 / \mathrm{kg}$ bahan baku. Sedangkan bagian tenaga kerja adalah rasio antara imbalan tenaga kerja dengan nilai tambah yang juga bernilai $0,74 \%$. Keuntungan yang diperoleh dari proses pengolahan ikan bandeng menjadi otak-otak ikan bandeng sebesar Rp. 2,827/kg bahan baku.

Berdasarkan hasil analisis, nilai tamabah yang diperoleh dari kegiatan pengolahan ini mencapai $0,26 \%$ dan dapat menguntungkan bagi pengolah ikan bandeng menjadi otak-otak ikan bandeng pada usaha otak-otak ikan bandeng. Walaupun demikian kegiatan pengolahan ini dinilai masih relatif kecil. Hal ini dipengaruhi oleh jumlah tenaga kerja pengolah ikan bandeng menjadi otakotak ikan bandeng masih sangat sedikit.

Margin adalah presentase yang besarnya dihitung berdasarkan angka penjualan dan produksi untuk menilai beberapa aspek dari profitabilitas usaha, marjin keuntun gan perusahaan mencapai $0,019 \%$.

\section{Kesimpulan}

Berdasarkan uraian hasil dan pembahasan, maka dapat disimpulkan dalam penelitian ini:

1. Proses pengolahan otak-otak ikan bandeng dilalukan melalui beberapa tahap yaitu : persiapan bahan baku, pembersihan dan pengeluaran isi perut, pemisan daging dengan kulit ikan, penggilingan daging ikan, pembuatan bumbu dan percampuran dengan daging, pengembalian adonan kedalam kulit, pegukusan, pendinginan, pengorengan dan pengemasan. 
2. Pengolahan ikan bandeng menjadi otak-otak ikan bandeng di Kecamatan Lamongan Kabupaten Lamongan memperoleh keuntungan sebesar Rp. 31.347.877 per delapan belas kali proses produksi selama satu bulan.

3. Pengolahan ikan bandeng menjadi otak-otak ikan bandeng di Kecamatan Lamongan Kabupaten Lamongan menghasilkan nilai tambah sebesar Rp. $10.900 / \mathrm{kg}$ bahan baku.

\section{DAFTAR PUSTAKA}

Hayami, Kawagoe, Marooka, Siregar. 1987. Agricultural Marketing and Processing in Upland Java. A Perspective From a Sunda Village, CGPRT. Bogor.

KKP. 2016.UPI-Menengah-Besar. Kementerian Kelautan dan Perikanan Republik Indonesia. Diakses: 06 Oktober

2016.http://kkp.go.id/wpcontent/uploads/2016/09/ UPI-MENENGAHBESAR.pdf.

Rachmansyah. 2004. Analisis Daya Dukung Lingkungan Perairan Teluk Awarange Kabupaten Barru, Sulawesi Selatan bagi Pengembangan Budidaya Bandeng dalam Keramba Jaring Apung. Sekolah Pascasarjana Institut Pertanian Bogor. Bogor. Disertasi.

Sugiyono. 2009/2010. Metode Penelitian Kuantitatif
Kualitatif \& RND.Bandung: Alfabeta. 